\title{
Joints with bars glued-in softwood laminated timber subjected to climatic cycles
}

\author{
D. Otero-Chans ${ }^{1}$, J. Estévez-Cimadevila ${ }^{1}$, E. Martín-Gutiérrez ${ }^{1}$ \\ (1) University of A Coruña, Department of Architectural, Civil and Aeronautical Building Structures, \\ Campus A Zapateira, 15071, A Coruña, Spain. \\ Corresponding author: marilo@udc.es (Dolores Otero-Chans) \\ ORCID:https://orcid.org/0000-0003-1738-252X (Dolores Otero-Chans) \\ https://orcid.org/0000-0002-8460-2097 (Javier Estévez-Cimadevila) \\ https://orcid.org/0000-0001-7464-4288 (Emilio Martín-Gutiérrez)
}

\begin{abstract}
The effect of climatic cycles (extreme temperatures and humidity) on the performance of joints made with threaded steel rods glued by two-component epoxy adhesive in softwood glulam timber is studied. Short-term tests have been made on three types of specimens: standard condition specimens $\left(20{ }^{\circ} \mathrm{C} / 65 \% \mathrm{RH}\right)$, specimens subjected to extreme temperature and humidity during its storage in climatic chamber in service load situation, and specimens in similar unloaded situation. The load capacity, the failure modes and the load-deflection curves have been compared for the different types of specimens. The obtained results do not show a clear influence of the previous exposition to extreme climatic situations in the strength of the joint. On the contrary, the stiffness of the joints, especially those with longer anchorage length, has been reduced up to $35 \%$ in the specimens that were previously subjected to climatic changes, both unloaded and in load service situation.
\end{abstract}

KEYWORDS: Epoxides; Wood and wood composites; Durability; Glued-in rods. 


\section{Introduction}

Joints made with bars or plates glued in timber have been used in Europe for the last 50 years, both for the rehabilitation or the reinforcement of existent structures and for the design of joints in new construction works. Glued-in rods exhibit great efficiency, high strength and stiffness with a ductile failure and the aesthetical and fire behaviour benefits derived from its hidden design inside the wooden pieces. Numerous studies to characterize the load capacity of these joints focused on evaluating the load capacity of a simple element according to the different parameters that define the joint: anchorage length, rod diameter, adhesive thickness, orientation of the joint with regard to the grain, etc. $[1,2]$. A smaller proportion of the studies has evaluated the behaviour of bar groups, mainly oriented to the analysis of the incidence of the separation between them $[3,4]$, or their behaviour when they are used in rigid joints of frames [5].

Most of the existing literature has focused on the analysis of the behavior of joints made on softwood glulam timber in short-length tests $[1,2]$, while the studies which have evaluated the behavior of rods glued in hardwood timber remain limited [6-13].

The influence of the anchorage length on the load-bearing capacity of the joint has been widely studied. Studies have proved that, in standard environmental conditions, the resistant capacity of the joint increases when the gluing area increases as well, both by an increase of the hole diameter or the increase of the anchorage length. However, the relation between the gluing area and the resistant capacity is not linear, so it is strongly influenced by the slenderness of the joint [2,14-18]. Literature agrees that the gluing area defines the resistance of the joint but there is still no final agreement regarding the quantification of that influence $[2,19]$. This becomes clear in the lack of a common European legislation that includes a clear regulation about the use and dimensioning of this kind of joints, in spite of the fact that numerous dimensioning formulas of experimental $[2,15,16,18]$ or analytical basis $[7,20-22]$ have been postulated. Although since the 90s several proposals of design rules for implementation in $\mathrm{EC}_{5}$ have been made, only a few European countries have a calculation model in their national standards, highlighting the one proposed by the German DIN rule as the most used design method $[1,19]$.

The behaviour of these joints in non-standardized environmental conditions has been a concern since the earliest studies. This concern is related both with the well-known sensibility of the adhesives' behaviour to extreme temperatures and with the fact that the strength and stiffness of wood is strongly conditioned by the moisture content. Additionally, the effect of the load duration and the creep of the wood, is also conditioned by the moisture content. Wood, as a hygroscopic material, modifies its moisture content as a function of the temperature and relative humidity of the air, and it is well known that as the moisture content of the wood increases, its strength decreases and its creep increases. This behaviour is considered in the standard design criteria through the use of the well-known modification factor for duration of load and moisture content $\left(\mathrm{k}_{\mathrm{mod}}\right)$ and the deformation factor $\left(\mathrm{k}_{\mathrm{def}}\right)$ [23]. The problem is complex and is additionally conditioned by the anisotropic character of the wood, according to which the intensity of the effect varies depending on the orientation of the effort in relation to the grain direction [24]. Many authors keep studying this complicated mechanical-supportive phenomenon of wood creeping, which does not have a precise model established yet, but there are some common conclusions, like the fact that creep is increased with the load duration and with the moisture content of wood. [25-29]. 
Currently, the Eurocode standard limits the use of glued joints in timber to service classes 1 and 2 (moisture content in timber not exceeding 20\%), regarding the problems in the glue/timber interface that can be derived from the movements generated by swelling and shrinkage [2].

The effect of load duration has also been studied in joints with glued-in rods. Existing studies seem to indicate that joints with glued-in rods subjected to long-term loads, compared to short-term loads, show a reduction of strength of similar magnitude to the one that would affect the wooden elements in the same situation [5,14,30].This is due to the fact that neither the bar nor the adhesive are affected by this factor. On the contrary, very different creep behaviours have been found when comparing different adhesives [21,31]. Verdet et al. [31] performed creep tests in a walk-in environmental chamber. Joints with epoxy adhesive demonstrated better behaviour than the ones with polyurethane. For epoxy specimens, they found that the residual strength of specimens after 30 days of creep loading at $70 \%$ stress level was not affected. In specimens with visible cracking, after being subjected to drying from $18 \%$ to $10 \%$, strength reduced by $22 \%$ and stiffness reduced by $17 \%$. They conclude creep behaviour is governed by temperature, but moisture content variations can generate damage in the connection as well.

Variations of air humidity and temperature can also affect the behaviour of the adhesive, although the obtained results have been different according to the type of adhesive that has been used, among other factors [30,32]. Most of the literature agrees that the behaviour of the joint is highly conditioned by the temperature, but some studies have concluded that the strength of the joints is not significantly affected by temperature variation, while the increase of humidity can generate a drop in the stiffness of joints [6]. Tests carried out with epoxy and polyurethane adhesives found a significant loss of strength for temperatures between $40-50^{\circ} \mathrm{C}$, and an almost negligible strength for temperatures beyond $100^{\circ} \mathrm{C}[8,20,30,33]$. Di Maria et al [34] carried out tests using two different two-component epoxy resins. Specimens was loaded (up to $50 \%$ of the average failure load of reference specimens) during the heating process in an electric oven. Temperature was raised up to $150^{\circ} \mathrm{C}$ and maintained until specimens failed. They found a significant decrease of the bond strength (around 50\%) respect to the reference specimens. Additionally, a "crumbling effect" was visible in the glueline of climatic specimens, showing a cohesive failure of the adhesive due to the increase of temperature combined with the application of a tension load.

This question becomes a very important aspect in the design of structures for a fire situation. In the case of joints made with glued bars, the design of the proper joint as hidden inside the wooden piece acts as self-protective of the adhesive connection [35]. The moisture content is also determining during the execution process of the joints, because high moisture contents can compromise the curing of the adhesive and its adherence to timber [36].

Cavalli et al [37] carried out test with epoxy specimens and full scale steel-timber epoxy joints exposed to various conditions and ageing cycles, including immersion in water (demineralized and swimming pool water), and exposure to different temperatures and relative humidity values. They found chemical transformations in the adhesive submersed in water for months and highlighted the caution needed for the use of glued-in joints in timber under severe conditions.

Existing studies in this field remain limited in number and conclusions regarding the influence of environmental conditions on the behaviour of glued-in joints are 
inconclusive, potentially influenced by the different test setups used. In some cases, specimens are introduced in electrical ovens until high temperatures are reached along the entire joint. Later, specimens are tested once they have reached the standard environmental conditions, obtaining what is called the "residual strength". In other cases, specimens are subjected to climatic cycles or are introduced in a furnace, which produce a gradient of variable temperatures along the joint. Any of these procedures could enhance a post-curing effect of the adhesive if specimens are unloaded during the heating process [34.37]. More detailed and extent studies to achieve a better knowledge of the behaviour of this type of joints in different environmental and thermal situations are necessary.

The aim of the present study is to evaluate the incidence of the exposure to extreme cycles of temperature and humidity of full scale joints made on glulam softwood timber with threaded steel rods glued parallel to grain. To that end, the structural behavior of specimens stored in standard environmental conditions on short-term tests was compared to the structural behavior of others subjected to climatic cycles, both in service load situation and unloaded.

\section{Material and methods}

\subsection{Specimens}

In a first stage, experiments were carried out on two types of specimens:

- REF specimens (reference): reference specimens which were tested after their storage in standard environmental conditions: $20^{\circ} \mathrm{C}$ and $65 \%$ of relative humidity (RH).

- CC-L specimens (climate cycles load): specimens that were tested after being subjected to extreme climatic cycles in service load situation.

Through the comparison between both types, the aim was to evaluate how the exposure to extreme climatic cycles of temperature and humidity affected the joints in real load situations. Two anchorage lengths were studied for each one of the two types of specimens, and for two of the tested anchorage lengths an additional type of specimens was made (CC-U). The CC-U specimens were introduced into the climatic chamber at the same time as their counterpart CC-L, but unloaded. This provided some additional information for the specimens with the most common joint lengths, giving rise to a third type of specimen:

- CC-U specimens (climate cycles unload): specimens that were tested after being subjected to extreme climatic cycles unloaded.

The specimens were made by using softwood glulam timber sections of quality GL$28 \mathrm{~h}[38]$, with a total length $\left(\mathrm{Lm}_{\mathrm{m}}\right)$ higher to the glued joint length $\left(\mathrm{Lg}_{\mathrm{g}}\right)$. The transversal section of the specimen was $160 \times 160 \mathrm{~mm}$. The density of the timber was determined for a wood humidity content of $12 \%$, obtaining an average value of $452.3 \mathrm{~kg} / \mathrm{m}^{3}$ (standard deviation 24.8).Threaded steel bars with a nominal diameter (d) of $12 \mathrm{~mm}$ and a quality of 10.9 [39] were used. The used adhesive was a two-component epoxy (HILTI HIT-RE 500) that had proved adequate for this application in previous tests, carried out in standard climatic conditions $\left(20^{\circ} \mathrm{C} / 65 \% \mathrm{RH}\right)[10-13,15]$. Component A was a bisphenol $\mathrm{A} / \mathrm{F}$ base epoxy resin with inorganic filler (30-40\% bisphenol-Aepoxy resin, 10-20\% bisphenol-F-epoxy resin, <15\% hexandiolglycidylether, $<10 \%$ alkylglycidylether)and the component B was an aliphatic polyamine with inorganic 
filler (30-40\% m-xylylene diamine), with a density of $1.5 \mathrm{~g} / \mathrm{cm}^{3}\left(20^{\circ} \mathrm{C}\right)$ and a viscosity of about $5 \mathrm{O} \mathrm{Pa} \cdot \mathrm{s}\left(23^{\circ} \mathrm{C}\right)$. Values provided by the manufacturer and other technical researches that have used the same commercial adhesive, largely utilized at the field of the structural anchoring, have been taken as reference $[40,41]$. The glass transition temperature of the adhesive is between $60-70^{\circ} \mathrm{C}$ according to these references. Due to the fact that the main objective of this paper was to evaluate the structural behaviour of the connections, both strength and stiffness, after have been subjected to extreme climatic conditions, the realization of further characterization tests for the adhesive was not considered necessary. The aforementioned studies [10-13,15] made with the same adhesive had proved also that the superficial treatment of the bars was not necessary, because the spigots of the threaded surface ensure the transmission of the load in the steel-adhesive contact surface in a mechanical way. The bars had a hot zinc treatment to avoid the possible corrosion of the steel as a result of the climatic cycles they were going to be submitted to. The threaded bars had a length of $150 \mathrm{~mm}$ longer than the anchorage length with the aim to enable their fixation to the grips of the test machine during the load process. The relationship between the bars diameter and the timber section provided a distance to the edge six times longer than the bar diameter (6d), with the aim of avoiding failure caused by timber splitting [3,10]. In the centre of the timber section drills of $14 \mathrm{~mm}$ diameter were made in the direction of the grain, which produced an adhesive thickness of $1 \mathrm{~mm}$. To evaluate the influence of anchorage length, specimens were made with three different anchorage lengths: 60, 120 and $180 \mathrm{~mm}$. The characteristics of the different types of tested specimens are summarized in table 1.

\begin{tabular}{ccccccccc}
\hline Type & $\begin{array}{c}\text { Anchorage } \\
\text { length }(\mathrm{Lg})\end{array}$ & $\begin{array}{c}\text { Timber } \\
\text { length } \\
(\mathrm{Lm}) \\
{[\mathrm{mm}]}\end{array}$ & $\begin{array}{c}\text { Rod } \\
\text { nominal } \\
\text { diameter } \\
{[\mathrm{mm}]}\end{array}$ & $\begin{array}{c}\text { Hole } \\
\text { diameter } \\
{[\mathrm{mm}]}\end{array}$ & $\begin{array}{c}\text { Average } \\
\text { density of } \\
\text { timber } \\
{[\mathrm{kg} / \mathrm{m} 3]}\end{array}$ & $\begin{array}{c}\text { Standard } \\
\text { deviation of } \\
\text { density }\end{array}$ & $\begin{array}{c}\text { Number of } \\
\text { specimens }\end{array}$ & $\begin{array}{c}\text { Load } \\
\text { during the } \\
\text { cycles } \\
{[\mathrm{kN}]}\end{array}$ \\
\hline $\mathrm{REF}$ & 60 & 90 & 12 & 14 & 438.15 & 15.74 & 8 & - \\
& 120 & 180 & 12 & 14 & 445.20 & 7.63 & 8 & - \\
& 180 & 250 & 12 & 14 & 452.32 & 13.27 & 8 & - \\
$\mathrm{CC}-\mathrm{U}$ & 120 & 180 & 12 & 14 & 450.86 & 30.99 & 8 & - \\
& 180 & 250 & 12 & 14 & 461.61 & 21.28 & 8 & - \\
$\mathrm{CC}-\mathrm{L}$ & 60 & 90 & 12 & 14 & 468.95 & 28.44 & 8 & 5.6 \\
& 120 & 180 & 12 & 14 & 432.79 & 36.26 & 8 & 8.8 \\
& 180 & 250 & 12 & 14 & 448.28 & 9.70 & 8 & 11.9 \\
\hline
\end{tabular}

Table 1. Types of tested specimens.

For each type of specimen and for each anchorage length 8 joints were tested, and provided a total of 64 results. Prior to the test, the specimens were stored in a climatic chamber with a temperature of $20^{\circ} \mathrm{C}$ and a relative humidity $(\mathrm{RH})$ of $65 \%$ until they reached a moisture content around $12 \%$. In order to determine the strength of the joints, the specimens were tested at a constant speed to reach failure in $5 \pm 2$ minutes. The load was applied by constant speed of the crosshead, with a speed of $0.3,0.5$ and $0.7 \mathrm{~mm} / \mathrm{min}$ for the lengths of 60,120 and $180 \mathrm{~mm}$, respectively. A pullcompression set-up was used, because the specimens were designed with only one glued joint on each end. To avoid the confinement effect, a steel plate with an $80 \mathrm{~mm}$ diameter hole was used over the head of the specimen, through which the pullthrough load was applied. In this way, there was a distance from the axis of the bar to 
the edge of the load three times superior to the bar diameter, as it is shown in Fig. 1. The tests were made in the laboratory of the Structural Timber Engineering Platform (PEMADE) of the University of Santiago de Compostela, using a test frame branded Microtest with load cell of $600 \mathrm{kN}$ branded Microtest and model PB2-F/600.

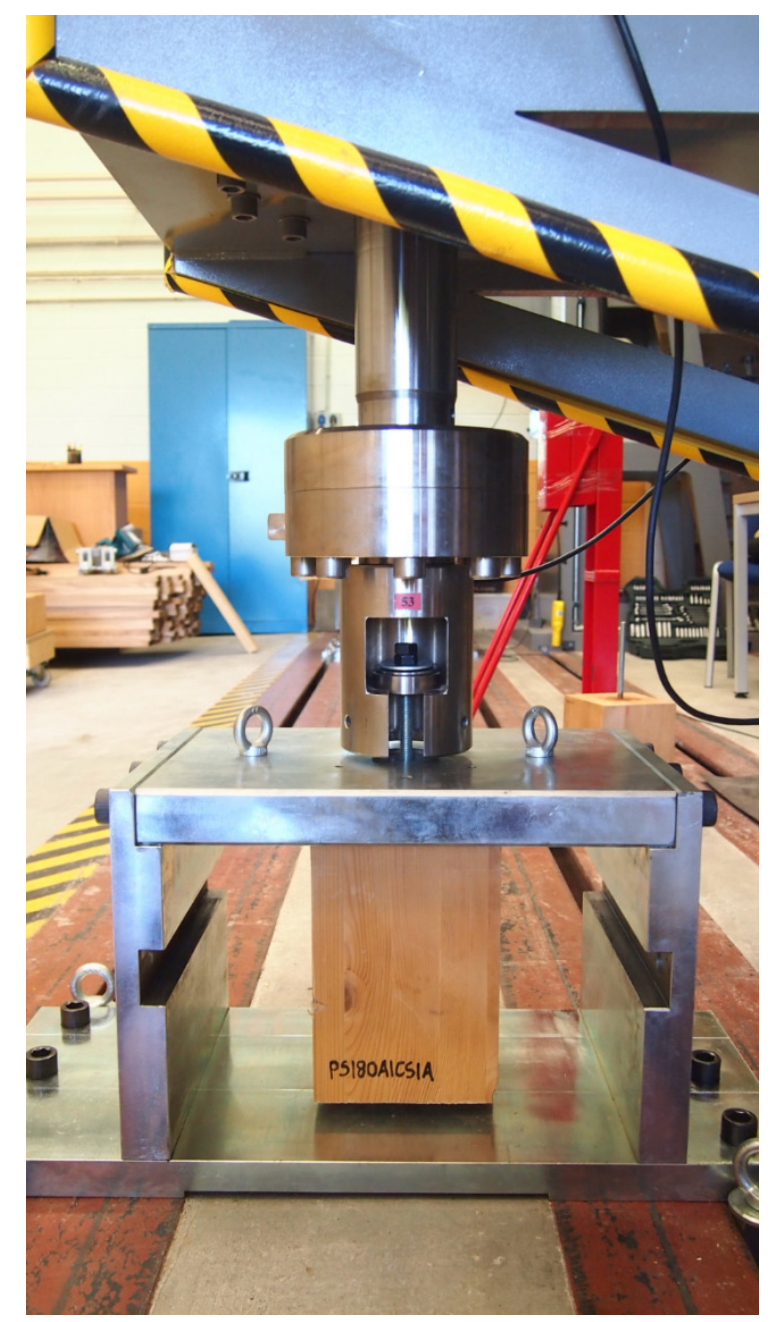

Fig. 1. Pull-compression test device.

\subsection{Climate built-up}

For the CC-L specimens to be in load service situation while subjected to climatic cycles, a pull-pull loading frame was designed using laminated steel sections, as it is described in Fig.2. For this purpose, the CC-L and CC-U specimens were initially made with a length of the timber piece double $\left(2 \mathrm{~L}_{\mathrm{m}}\right)$ of the finally tested specimens $\left(\mathrm{L}_{\mathrm{m}}\right)$. Four specimens were made for each type and each gluing length. At the end of each wooden piece, a glued joint with identical characteristics was manufactured, which allowed the use of the pull-pull device to apply the load during the storage process in climatic cycles. Once the climatic cycles were finished and the standard balance humidity recovered $\left(20^{\circ} \mathrm{C} / 65 \% \mathrm{RH}\right)$, the wooden pieces were cut in half their length. In this way, eight glued joints were obtained for each one of the three gluing lengths $\left(\mathrm{L}_{\mathrm{m}}\right)$ described in table 1 . 

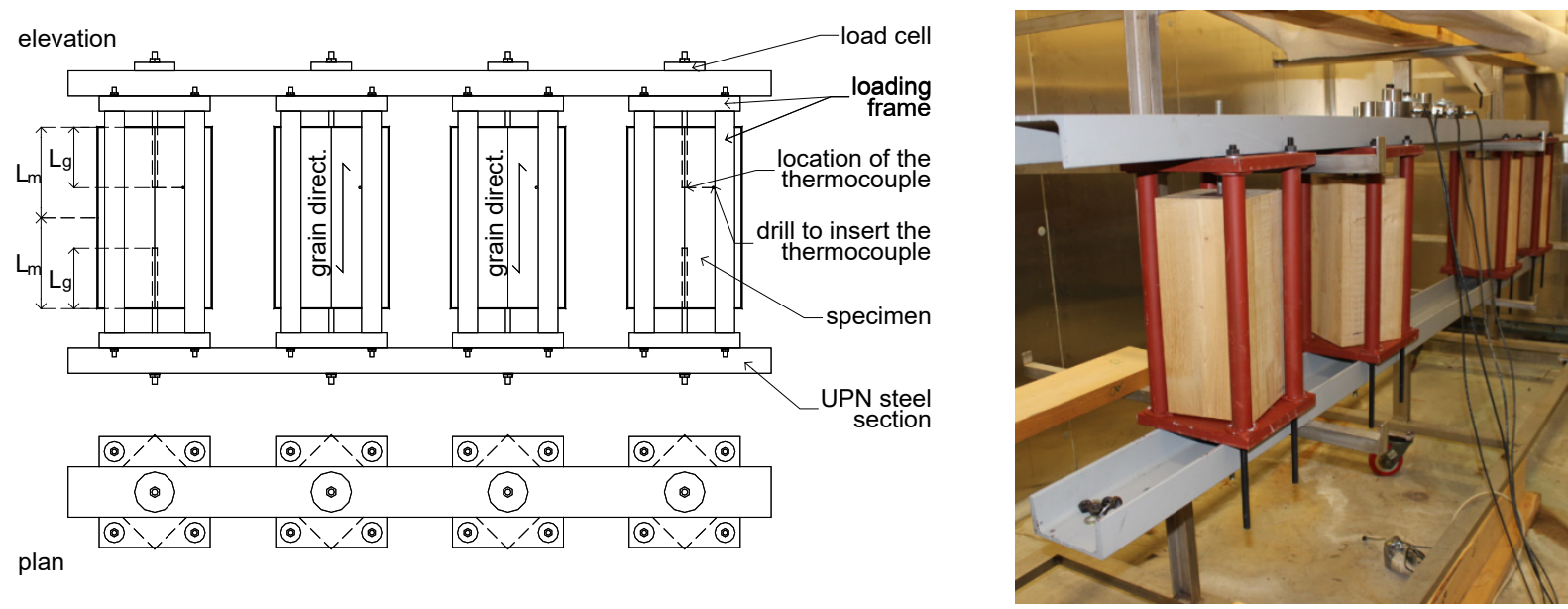

Fig. 2. Scheme of the pull-pull frame designed to apply load in the glued joints during the exposure to climatic cycles (CC-L), and specimens during their assembly.

For each anchorage length, thermocouple sensors were disposed in two of the wooden pieces subjected to load during the climatic cycles (CC-L), which allowed to register the variation of temperature of the joints during the cycles. To place each sensor, a $3 \mathrm{~mm}$ diameter hole was drilled in the centre of one lateral side of the wooden piece to a $\mathrm{Lg}$ distance from the superior edge, corresponding with the interior end of the glued joint. Then, a type $\mathrm{K}$ thermocouple sensor was introduced, which is valid for a range of temperatures from $-30^{\circ} \mathrm{C}$ to $+225^{\circ} \mathrm{C}$. Finally, the hole was sealed with MS polymer adhesive with high resistance to inclemency and UV rays. The specimens were stored in a standard environment until they reached a moisture content around $12 \%$ before proceeding to the gluing of the thermocouples.

\subsection{Climate cycles}

There is not a specific standard to evaluate the behaviour of aforementioned joints facing extreme climatic cycles. Neither is there an equivalence of these cycles with a natural aging process, e.g. for extrapolation of possible long-term analysis. On the other hand, the requirements of the ISO rule 9142 [42] exceeded the capabilities of the only available climatic chamber. On this basis, the proposed cycles on the rule UNE-EN 302-3:2005 [43] have been taken as a reference, including a phase of standard atmosphere (phase 0 ) which is introduced as an intermediate step between successive cycles.

In this way, the cycle designed for the test, compounded by four phases (A, B, C and o), had a total duration of 56 hours and was allocated as follows:

- Phase A: a target temperature of $50^{\circ} \mathrm{C}$ and a relative humidity of $87.5 \%$ during 24 hours.

- Phase B: a target temperature of $10^{\circ} \mathrm{C}$ and a relative humidity of $87.5 \%$ during 8 hours.

- Phase C: a target temperature of $50^{\circ} \mathrm{C}$ and a relative humidity of $20 \%$ during 16 hours.

- Phase o: Return to the initial situation of a standard atmosphere, a target temperature of $20^{\circ} \mathrm{C}$ and a relative humidity of $65 \%$ during 8 hours. 
Every 56-hour cycle was repeated 4 times, so the whole duration of the process amounted to 224 hours. Before and after testing them, the specimens were stored in standard atmospheric conditions (phase o) until they reached a relative humidity around $12 \%$. The humidity content control was made with a 2-pins digital wood moisture meter.

The phases that were proposed involved some theoretical variations on the timber moisture content, from 5 to $20 \%$, although the work conditions in the climatic chamber set some differences between the theoretical proposed cycle and the real cycles to which the specimens were subjected.

Firstly, the step from one phase to another was not immediate, because the climatic chamber needs a period of time to modify the atmospheric conditions between phases. Fig.3 shows the measurements of temperature and relative humidity registered by the climatic chamber for the specimen's case of $\mathrm{Lg}_{\mathrm{g}}=120 \mathrm{~mm}$. Due to the necessity of adapting the loading frame shown in Fig. 2 to the dimensions of each series of specimens according to their total length, the process was made independently for each of the three tested anchorage lengths. CC-L and CC-U specimens with the same anchorage length were subjected to the climatic cycles at the same time, the first ones set on the loading frame shown in Fig.2 and the second ones stacked into the frame. The graphics for specimens of $\mathrm{Lg}_{\mathrm{g}}=60 \mathrm{~mm}$ and $\mathrm{Lg}_{\mathrm{g}}=180 \mathrm{~mm}$ presented similar registrations to the ones of Fig.3. The climatic chamber measured the duration of the cycle from the moment when the target conditions were reached, so the total duration was superior to the theoretical 224 hours, as it can be observed in Fig.3.

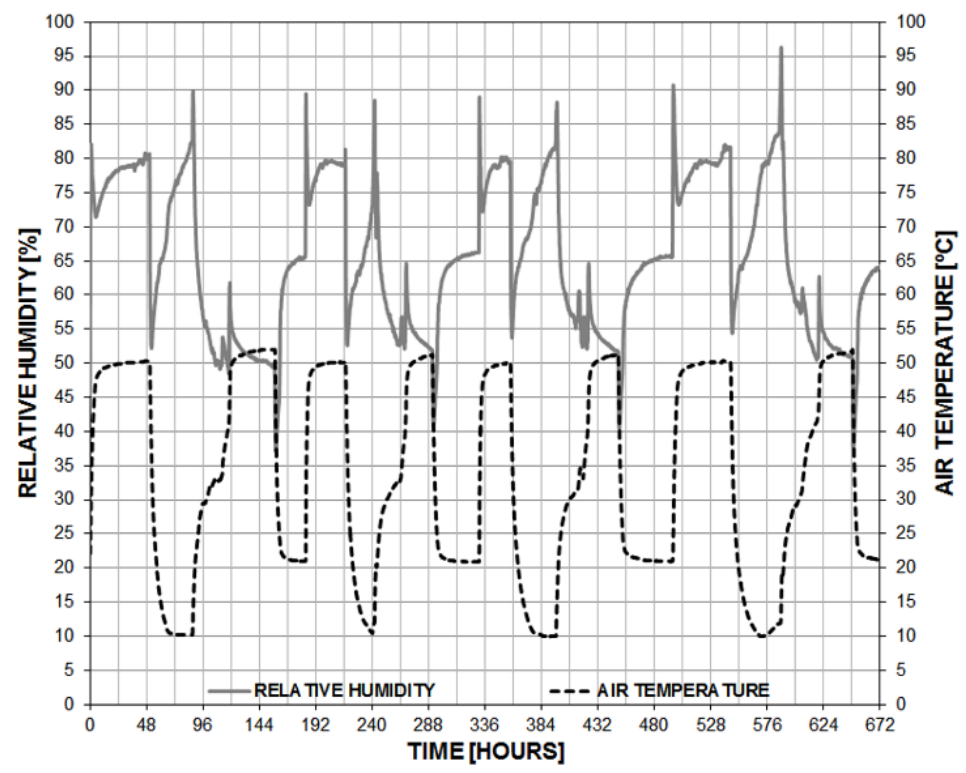

Fig. 3. Complete temporal development of the four proposed climatic cycles. Specimens with $\mathrm{Lg}=120 \mathrm{~mm}$.

On the other hand, Fig.3 also reveals the difficulty of maintaining the extreme ranges of temperature and relative humidity, expected to be $87.5 \%$ and $20 \%$. In spite of the fact that these values were punctually reached, during their cycles their value tended to stabilizes at around $80 \%$ for A and B phases, and $40 \%$ for phase $\mathrm{C}$. In this way, the timber humidity content finally varied between 20 and 6\%, as it is shown in Fig.4, made according to the hygroscopic balance curves by Kollmann [44] 


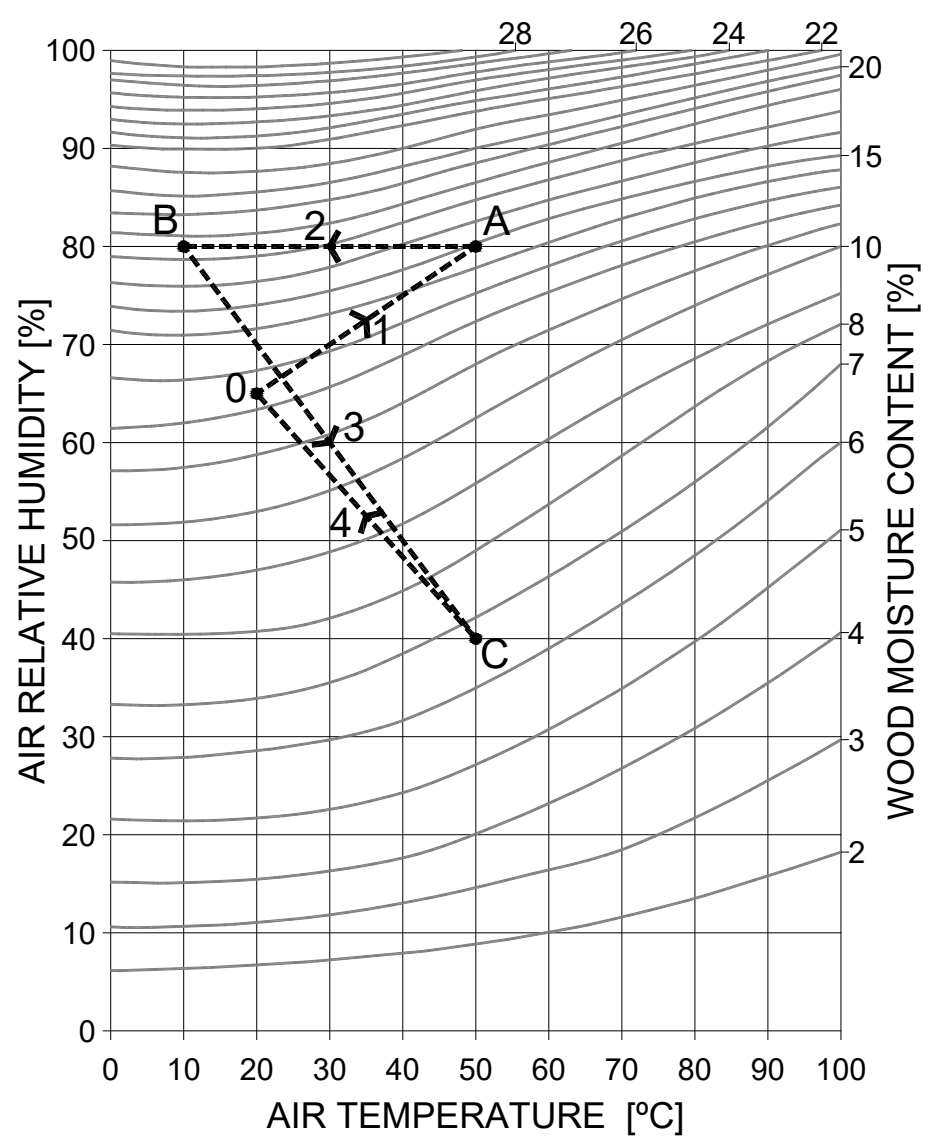

Fig. 4. Variation of the moisture content of timber specimens according to Kollmann balance curves.

\subsection{Serviceability load for specimens type CC-L}

The objective of the experimental analysis of the CC-L test pieces was to know the structural behaviour of joints subjected to load under climatic cycles in a situation as similar as possible to that of a real structure, so the actual standard procedure for the design of joints in wooden structures was taken into account. During the working life of a building structure, the usual loading situation corresponds to the so-called quasipermanent combination [45], used to determine the load value to which each of the tested specimens must be subjected. The starting point was the characteristic axial strength obtained for reference specimens ( $\mathrm{R}_{\mathrm{k}}$ of REF specimens), tested in standard conditions without being previously subjected to any load or climatic cycles. The calculation value of the joint resistance $\mathrm{R}_{\mathrm{d}}$ (design value of a load-carrying capacity), was determined according to Eurocode [23], taking into account the partial factor for a material property $\left(\gamma_{\mathrm{M}}\right)$ and the modification factor for duration of load and moisture content $\left(\mathrm{k}_{\mathrm{mod}}\right)$. Such resistance must not be surpassed by the effect of increased actions in characteristic combination, considered as the most unfavourable dimensioning load.

On the other hand, the quasi-permanent combination was defined as a representative service situation of the usual loading situation of the building [45]. In this way, with the aim of selecting a representative load value for the use situation of the structure, the percentage of the load that corresponds to the quasi permanent situation in service values in relation with the most unfavourable dimensioning load $(\Phi)$ was evaluated according to: 


$$
F[\%]=\frac{G_{k}+\stackrel{a}{ } Q_{k} \times Y_{2, Q}}{g_{G} \times G_{k}+g_{Q, 1} \times Q_{k, 1}+\stackrel{a}{a} Y_{0, Q, i} \times g_{Q, i} \times Q_{k, i}} \times \frac{k_{\text {mod }}}{g_{M}} \times 100
$$

Where:

$\mathrm{G}_{\mathrm{k}}=$ Characteristic value of the permanent action

$\mathrm{Q}_{\mathrm{k}}=$ Characteristic value of a single variable action

$\mathrm{Q}_{\mathrm{k}, 1}=$ Characteristic value of the leading variable action 1

$\mathrm{Q}_{\mathrm{k}, \mathrm{i}}=$ Characteristic value of the accompanying variable action $\mathrm{i}$

$\mathrm{k}_{\bmod }=$ Modification factor for duration of load and moisture content

$\gamma_{\mathrm{G}}=$ Partial factor for permanent actions

$\gamma_{M}=$ Partial factor for a material property $\left(\gamma_{M}=1.3\right.$ for connections $)$

$Y_{Q}=$ Partial factor for variable actions

$\psi_{\mathrm{o}}=$ Factor for combination value of a variable action

$\psi_{2}=$ Factor for quasi-permanent value of a variable action

According to (1) different usage possibilities were analysed to determine the percentages of service load that need to be considered $(\Phi)$, taking into account the most common types of timber structures. As it is summarized in Table 2, these values of service loads moved between $29 \%$ and $34 \%$ from the characteristic load, so it was preferable to take a $30 \%$ of the characteristic failure load obtained for the reference specimens. The applied preloading values that resulted from considering this percentage have been reflected in Table 1 . This load was applied using a torque wrench until the load cells placed on the ends of the specimens, as it is indicated in Fig.2, showed the desired readout.

\begin{tabular}{|c|c|c|c|}
\hline Category of use & Permanent actions & Variable actions & $\Phi[\%]$ \\
\hline $\begin{array}{l}\text { A:residential areas } \\
\text { B: office areas }\end{array}$ & $\begin{array}{c}\text { self weight, } G_{k}=1.0 \mathrm{kN} / \mathrm{m}^{2} \\
\text { finishes, } G_{k}=1.0 \mathrm{kN} / \mathrm{m}^{2} \\
\text { partitioning, } G_{k}=1.0 \mathrm{kN} / \mathrm{m}^{2} \\
\qquad \gamma_{\mathrm{G}}=1.35\end{array}$ & $\begin{array}{c}\mathrm{Q}_{\mathrm{k}}=2.0 \mathrm{kN} / \mathrm{m}^{2} \\
\gamma_{\mathrm{G}}=1.50 \\
\mathrm{k}_{\bmod }=0.8 \text { and } \psi_{2}=0.3\end{array}$ & $31.4 \%$ \\
\hline C: congregation areas (low) & $\begin{array}{c}\text { self weight, } G_{k}=1.0 \mathrm{kN} / \mathrm{m}^{2} \\
\text { finishes, } G_{k}=1.0 \mathrm{kN} / \mathrm{m}^{2} \\
\text { partitioning, } G_{k}=1.0 \mathrm{kN} / \mathrm{m}^{2} \\
\qquad \gamma_{\mathrm{G}}=1.35\end{array}$ & $\begin{array}{c}\mathrm{Q}_{\mathrm{k}}=3.0 \mathrm{kN} / \mathrm{m}^{2} \\
\gamma_{\mathrm{G}}=1.50 \\
\mathrm{k}_{\text {mod }}=0.8 \text { and } \psi_{2}=0.6\end{array}$ & $34.5 \%$ \\
\hline $\begin{array}{l}\text { C: congregation areas (high) } \\
\text { D: shopping areas }\end{array}$ & $\begin{array}{c}\text { self weight, } G_{k}=1.5 \mathrm{kN} / \mathrm{m}^{2} \\
\text { finishes, } G_{k}=1.0 \mathrm{kN} / \mathrm{m}^{2} \\
\gamma_{\mathrm{G}}=1.35\end{array}$ & $\begin{array}{c}\mathrm{Q}_{\mathrm{k}}=5.0 \mathrm{kN} / \mathrm{m}^{2} \\
\gamma_{\mathrm{G}}=1.5 \mathrm{O} \\
\mathrm{k}_{\bmod }=0.8 \text { and } \psi_{2}=0.6\end{array}$ & $31.1 \%$ \\
\hline $\begin{array}{l}\text { H: roofs, only accessible for } \\
\text { maintenance }\end{array}$ & $\begin{array}{c}\text { self weight, } G_{k}=1.0 \mathrm{kN} / \mathrm{m}^{2} \\
\text { finishes, } G_{k}=1.0 \mathrm{kN} / \mathrm{m}^{2} \\
\gamma_{\mathrm{G}}=1.35\end{array}$ & $\begin{array}{c}\mathrm{Q}_{\mathrm{k}}=1.0 \mathrm{kN} / \mathrm{m}^{2} \\
\gamma_{\mathrm{G}}=1.5 \mathrm{O} \\
\mathrm{k}_{\mathrm{mod}}=0.8 \text { and } \psi_{2}=\mathrm{o}\end{array}$ & $29.3 \%$ \\
\hline
\end{tabular}

Table 2. Evaluation of the percentage of service load $(\Phi)$ for different design situations.

\section{Results and Discussion}

\subsection{Failure modes and loads}

The joints of CC-U and CC-L specimens were subjected to a visual inspection after being subjected to climatic cycles. Neither visual damage nor any liquefaction of the 
adhesive was observed. On the other hand, the readings of the load cells in CC-L specimens were checked after end of the setting process inside the climatic chamber finished. The readings were reduced by an average of $15 \%$ regarding the initial loads applied to them. This is easily explained taking into account the phenomenon of creep deflections [30], since, as it has been explained on section 2.2, the loads during the process of the climatic cycles were applied using a fix frame, and this process was extended for about 28 days (Fig. 3).

During that period, the environmental conditions swung their moisture content between 6 and 20\%. The visual inspection of the specimens did not reveal the existence of cracks despite both shrinkage and swelling of wood.

Specimens were tested until failure in short-term tests, once they had been subjected to the climatic cycles described in section 2.1, and after reaching the balance humidity in a standard atmosphere. The control of the moisture content was made with a 2pins digital wood moisture meter. For every type of specimen, the failure mode was the partial extraction of the bar due to shear failure of timber on timber/adhesive interface. As it is shown in Fig. 5, in some cases the extraction was accompanied by small blocks of the adjacent timber, although always of small dimensions. No differences of failure between the different types of specimen tested were observed.

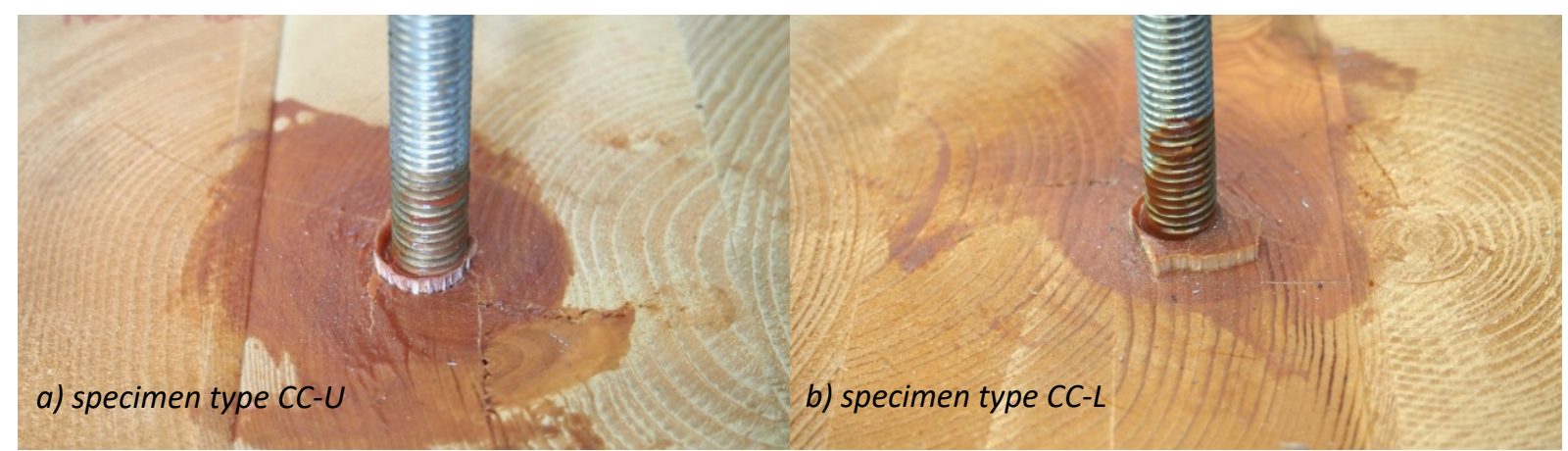

Fig.5. Failure mode presented by all the tested specimen after testing them until failure. Shear failure on timber/adhesive interface.

In Table 3 the average values of failure load obtained for each type of specimen are summarized. Additionally, the standard deviation and the characteristic value calculated according to the Eurocode [45] are indicated.

Firstly, the values for the three types of specimen with the same anchorage length are compared; thus, it is pretended to evaluate the incidence of the exposure to the cycles in the joint resistance. The comparison is made numerically in the table 3 and graphically in Fig. 6. Fig. 6 provides a representation of the shear load values of all the tested specimens. The obtained results do not allow establishing final conclusions. Paying attention to the average values of the failure load, in the case of the anchorage lengths of 120 and $180 \mathrm{~mm}$, the capacity of the joints is reduced to $13 \%$ and $9 \%$, respectively when they are subjected to climatic cycles with load. The strength of specimens with an anchorage length of $120 \mathrm{~mm}$ is reduced by $16 \%$ when they are subjected to climatic cycles unloaded. However, both CC-L/6o and CC$\mathrm{U} / 180$ specimens practically maintain the reference value with a variation of nearly $2 \%$. On the other hand, due to the existing differences in standard variations of the different types, these relations are not maintained when we consider the characteristic failure loads of the joints. 


\begin{tabular}{|c|c|c|c|c|c|c|c|}
\hline $\begin{array}{l}\text { Type of } \\
\text { specimen }\end{array}$ & $\begin{array}{c}\text { Load during the } \\
\text { climatic cycles } \\
{[\mathrm{kN}]}\end{array}$ & $\begin{array}{c}\text { Average } \\
\text { failure load } \\
{[\mathrm{kN}]}\end{array}$ & $\begin{array}{c}\text { Standard } \\
\text { deviation } \\
- \\
\end{array}$ & $\begin{array}{c}\text { Characteristic } \\
\text { failure load } \\
{[\mathrm{kN}]}\end{array}$ & $\begin{array}{c}\text { Variation of } \\
\text { gluing area } \\
\% \\
\end{array}$ & $\begin{array}{c}\text { Variation of } \\
\text { average failure load } \\
\% \\
\end{array}$ & $\begin{array}{c}\text { Variation of } \\
\text { charact. failure load } \\
\% \\
\end{array}$ \\
\hline \multicolumn{8}{|c|}{ COMPARISON BY TYPE OF SPECIMEN for the same gluing lengths } \\
\hline REF 60 & - & 21.33 & 1.59 & 18.57 & - & $100.00 \%$ & $100.00 \%$ \\
\hline CC-L 60 & 5.6 & 21.70 & 2.44 & 17.44 & - & $101.70 \%$ & $93.94 \%$ \\
\hline REF 120 & - & 46.43 & 8.86 & 31.00 & - & $100.00 \%$ & $100.00 \%$ \\
\hline CC-U 120 & - & 39.00 & 6.83 & 27.11 & - & $84.00 \%$ & $87.46 \%$ \\
\hline CC-L 120 & $9 \cdot 3$ & 40.38 & 2.70 & 35.69 & - & $86.97 \%$ & $115.11 \%$ \\
\hline REF 180 & - & 53.02 & 6.81 & 41.16 & - & $100.00 \%$ & $100.00 \%$ \\
\hline CC-U 180 & - & 54.01 & 6.30 & 43.06 & - & $101.87 \%$ & $104.60 \%$ \\
\hline CC-L 180 & 12.3 & 48.33 & 5.64 & 38.52 & - & $91.16 \%$ & $93.57 \%$ \\
\hline \multicolumn{8}{|c|}{ COMPARISON BY GLUING LENGTH for the same type of specimens } \\
\hline REF 60 & - & 21.33 & 1.59 & 18.57 & $33.33 \%$ & $40.23 \%$ & $45.11 \%$ \\
\hline REF 120 & - & 46.43 & 8.86 & 31.00 & $66.67 \%$ & $87.56 \%$ & $75 \cdot 32 \%$ \\
\hline REF 180 & - & 53.02 & 6.81 & 41.16 & $100.00 \%$ & $100.00 \%$ & $100.00 \%$ \\
\hline $\mathrm{CC}-\mathrm{U} 120$ & - & 39.00 & 6.83 & 27.11 & $66.67 \%$ & $72.21 \%$ & $62.97 \%$ \\
\hline CC-U 180 & - & 54.01 & 6.30 & 43.06 & $100.00 \%$ & $100.00 \%$ & $100.00 \%$ \\
\hline CC-L 6o & 5.6 & 21.70 & 2.44 & 17.44 & $33.33 \%$ & $44.89 \%$ & $45.29 \%$ \\
\hline CC-L 120 & 9.3 & 40.38 & 2.70 & 35.69 & $66.67 \%$ & $83.54 \%$ & $92.65 \%$ \\
\hline CC-L 180 & 12.3 & 48.33 & 5.64 & 38.52 & $100.00 \%$ & $100.00 \%$ & $100.00 \%$ \\
\hline
\end{tabular}

Table 3. Values of failure load.

Then, the influence of the anchorage length on the load-bearing capacity of the joint was studied comparing test results for the same type of specimen. The results are shown both in Table 3 and in Fig.7. Table 3 additionally indicates the variation of the interface timber-adhesive (gluing area), which in this case varies linearly with the length, since the drill and the threaded bar diameter were the same in all cases. Reference specimens show a behaviour in line with the already mentioned and wellknown in the literature. The strength of the joint increases when the gluing length increases, but the percentage of the load increase is lower to the increase of the gluing area. The specimens that have been subjected to climatic cycles, both loaded and unloaded, show a similar behaviour to the reference specimens. The percentages that represent the increase of strength are similar to the ones of the specimens that have not been subjected to climatic cycles.

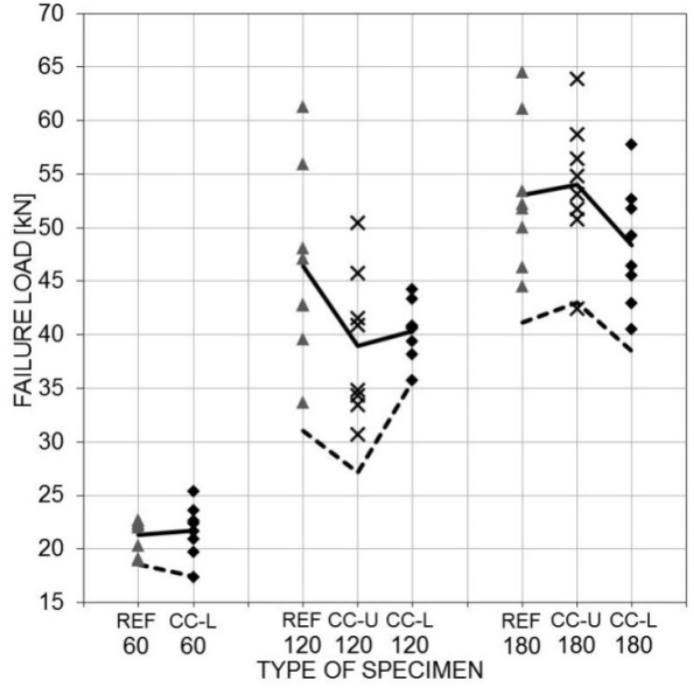

Fig. 6.Failure load values. Comparison of results according to anchorage length. (Solid lines: average values. Dashed lines: characteristic values).

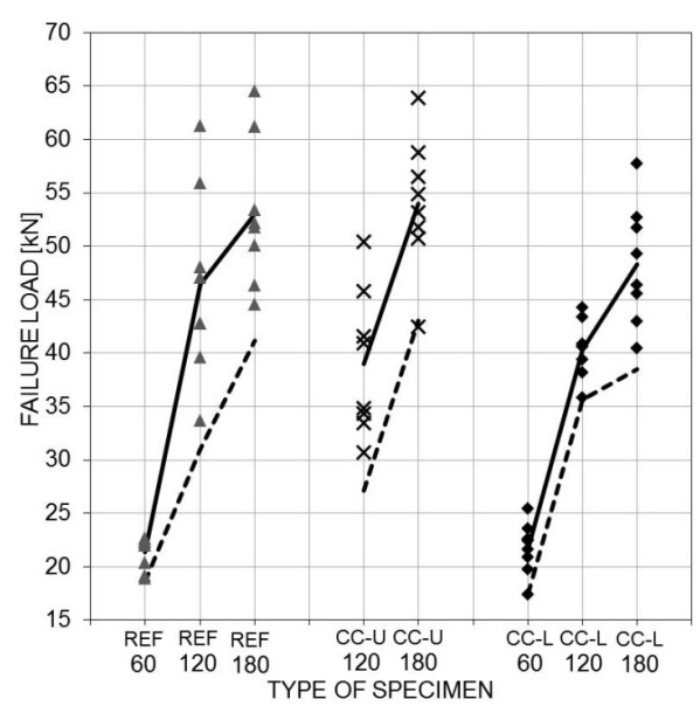

Fig. 7. Failure load values. Comparison of results by specimen type. (Solid lines: average values. Dashed lines: characteristic values). 


\subsection{Evolution of temperature in the joint.}

As it has been shown in the section 3.1, there is not any clear evidence that the strength of the joints tested in standard conditions has been affected after being subjected to temperatures up to $50^{\circ} \mathrm{C}$ with relative humidity above $80 \%$. Another important aspect in the implementation of glued-in rods is to evaluate the level of self-protection guaranteed by the hidden-design of the joints in fire situations. In order to evaluate the protection level in the tested joints, the readouts that correspond to the thermocouples, inserted into the glued joints as it has been described in the section 2.1, have been analysed with great detail, in relation with the climatic variations produced in the chamber. In Fig. 8 it is represented the case of the first 10 hours of the climatic cycles that correspond to the bars of $\mathrm{Lg}_{\mathrm{g}}=120 \mathrm{~mm}$, although the described situation is reproduced almost identically for other lengths and other phases of the test. It can be appreciated that the readouts that were registered by the thermocouples disposed for each series of specimens were practically the same. Since the first half an hour the relative humidity of the air varied between $71 \%$ and $83 \%$. In those conditions, the span of time since the temperatures of $30,35,40$ and $45^{\circ} \mathrm{C}$ are reached until the thermocouples placed on the interior end of the joints register the same values, is measured. As it can be seen in Fig. 8 the readouts of the thermocouples start from a balance temperature of $20^{\circ} \mathrm{C}$ and the spans of time that take the interior of the joint until it reaches the chamber temperature are longer as long as the temperature rises. The minimum delay is two hours for $30^{\circ} \mathrm{C}$ and almost 4 hours in the case of $45^{\circ} \mathrm{C}$. This should indicate that, even in the case of using adhesives with reduced glass transition temperatures, we could easily design joints with high resistance to fire by increasing the wood section if it was needed. This is so even when steel threaded bars with a high capacity of heat transfer are used.

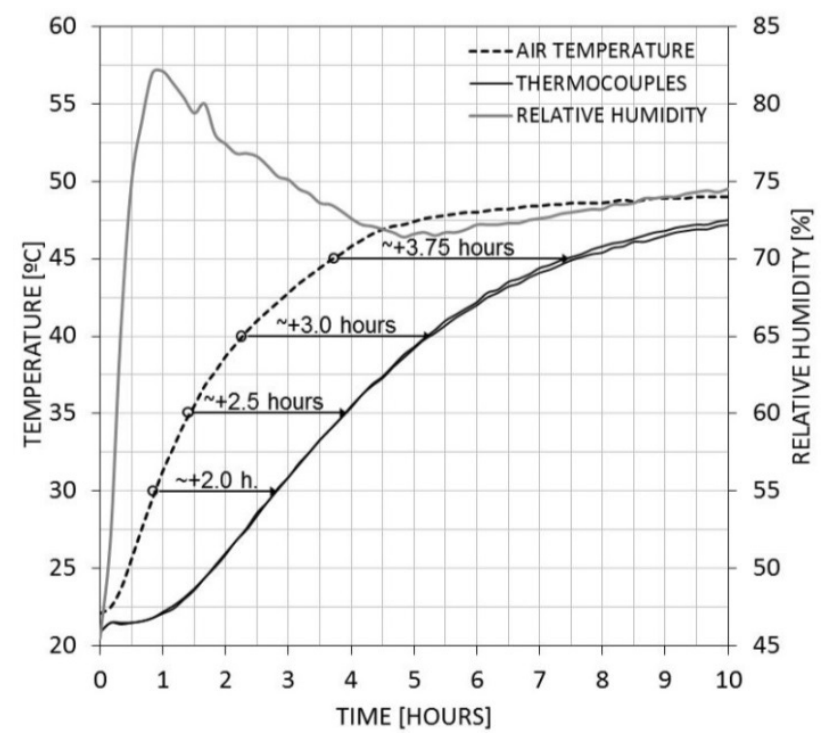

Fig. 8. Readouts of the thermocouples, environment temperature and relative humidity between o and 10 hours of the process in the climatic chamber for specimens with $\mathrm{Lg}_{\mathrm{g}}=120 \mathrm{~mm}$.

The protection of the joint against the variation of external temperatures can be modified both according to the distance to the edge and to the type of wood that is used. According to literature, the thermal conductivity coefficient $(\lambda)$ increases with timber density, so this means that the types of timber with lower densities are better thermal insulators, because they have a more reduced heat transmission speed [46]. 
This aspect has been proved by comparing the results shown in the present paper, for specimens of softwood glulam timber with an average density of $452.3 \mathrm{~kg} / \mathrm{m}^{3}$, with the ones obtained for specimens with similar characteristics made on chestnut timber with an average density of $583.5 \mathrm{~kg} / \mathrm{m}^{3}$. The time spans that were registered in the case of chestnut specimens were 1.6 and 2.3 hours for $42^{\circ} \mathrm{C}$ and $45^{\circ} \mathrm{C}$ respectively [47].The difference in results reveals the importance of analysing the behaviour of these types of joints in different wood species.

\subsection{Influence on the stiffness of the joint.}

Some authors have indicated that the increasing of temperature can alter the behaviour of the adhesive, indicating that glued joints lose stiffness when temperature rises $[6,20]$, but they recover it when the environmental conditions go back to normal. In the tests presented in this paper, the joints have been subjected to temperature and humidity cycles, but they were tested in standard environmental conditions and after having reached the balance humidity.

The load-displacement curves that correspond to the tests of the different types of studied joints are represented in Fig.9 for the three tested anchorage lengths. In order to assess the difference in behaviour between the three types of tested joints, it was represented with a different colour for each type of test, a graphic that corresponds to the specimen that reached the closest failure load to the average. To even the initial routes corresponding to the loading of the specimens, the value corresponding to a load of $5 \mathrm{kN}$ was took as one of zero displacement.
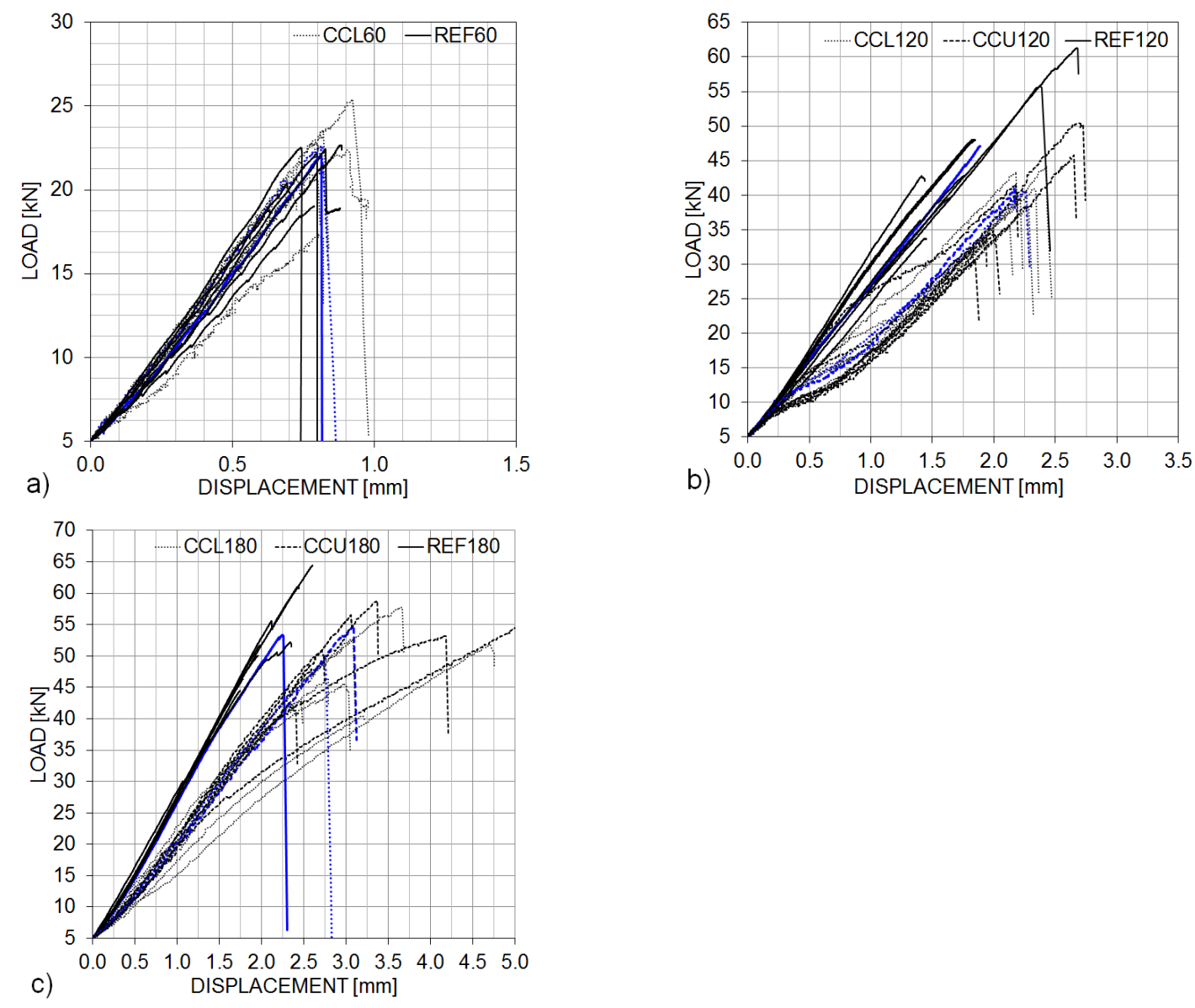

Fig.9. Load-displacement curves for specimens with $\mathrm{Lg}_{\mathrm{g}}=60 \mathrm{~mm}(\mathrm{a}), 120$ (b) and 180 (c) mm, respectively. 
The differences are significant between curves of smaller anchorage lengths (Fig. 9a, $\mathrm{L}_{\mathrm{g}}=60 \mathrm{~mm}$ ) and the specimens with higher anchorage lengths (Figs. 9b and 9c). In the case of the specimens with less anchorage length there is not any significant difference in the displacement recorded for the three types of tested specimens (REF, CCU, CCL). In both Figs. 9b) and 9c) it can be observed that both loaded (CCL) and unloaded (CCU) specimens present practically identic load-displacement curves, while the reference specimens (REF) present a load-displacement curve with deflections that are about 35\% smaller than the previous ones. This difference of behaviour between the shortest and the longest joints was also found in previous studies performed on chestnut timber [47]. The explanation of this phenomenon could come from the difference in the distribution of shear stresses along the joint according to its slenderness. The existing studies indicate that in reduced anchorage lengths, the stresses along the joint are quite even, and as long as the length increases, more stress peaks are produced at the ends of the joints $[7,21,36,48]$. In longer joints, those highest stress peaks are located on the exterior end of the joint, which coincides with the adhesive area that is the most exposed to climatic conditions, since, as we have seen, on the inner area of the joint, wood behaves as a retardant barrier for heat. The results seem to indicate that the exposure to high temperatures can alter the load-deflection response of the joints, even when they have recovered the standard environmental conditions. This is a very important aspect that has to be deeply studied, because of the consequent reduction on the stiffness of the joints.

\section{Conclusions}

Short-term tests have been conducted on 64 joints made with threaded steel bars glued parallel to grain in softwood laminated timber elements with a quality of GL28h. Residual strength and stiffness corresponding to three environmental situations have been compared: specimens in a standard environment and specimens subjected to extreme variations of temperature and humidity in a climatic chamber, both in service load and unloaded.

The joints were subjected to climatic cycles during 28 days with the relative humidity varying from $20 \%$ to $87.5 \%$ and the temperature from $10^{\circ} \mathrm{C}$ to $50^{\circ} \mathrm{C}$. In none of the samples that were visually inspected appeared any crack related to dimensional variations or stresses generated by those movements.

Joints made with bars glued on timber, by their self-protective form, allow designing high resistance joints in the case of fire. For joints made with $12 \mathrm{~mm}$ diameter bars, with a distance to the edge of six times the diameter of the bar, the rise of temperature was slowed down inside the joint between 180 and 230 minutes for temperatures up to $45^{\circ} \mathrm{C}$.

The exposure to extreme climatic cycles seems to modify the stiffness of the adhesive, reducing it around a $35 \%$ in this case.

The failure load values for specimens tested in usual standard conditions were, in some cases, $15 \%$ more than the ones that had been previously subjected to climatic cycles. However, this reduction on the load capacity of the specimens that were previously subjected to climatic cycles was not constant and, in some types of specimens, the failure load values were almost constant for the three types of tests that were conducted. Analysing the average failure load values, the joints subjected to climatic cycles keep less residual strength than the reference ones, but the results 
were not conclusive when the characteristic values were evaluated. Therefore, it will be necessary to make additional studies focused on the behaviour of joints made with glued bars subjected to extreme environments.

\section{References}

[1] Steiger R, Serrano E, Stepinac M, Rajcic V, O’Neill C,McPolin D, Widmann R. Strengthening of timber structures with glued-in rods. Construction and Building Materials 2015; 97:90-105.

[2] Tlustochowicz G, Serrano E, Steiger R. State-of-the-art review on timber connections with glued-in steel rods. Materials and Structures 2011; 44:997-1020.

[3] Gonzalez E, Avez C, Tannert T. Timber joints with multiple glued-in steel rods. Journal of Adhesion 2016;92:635-651.

[4] Parida G, Johnsson H, Fragiacomo M. Provisions for Ductile Behavior of Timber-to-Steel Connections with Multiple Glued-In Rods. J StructEng 2013;139:1468-1477.

[5] Fragiacomo M, Batchelar M. Timber Frame Moment Joints with Glued-In Steel Rods. II: Experimental Investigation of Long-Term Performance. J StructEng 2012;138:802-811.

[6] Hunger F, Stepinac M, Rajcic V, van de Kuilen J-WG.Pull-compression tests on glued-in metric thread rods parallel to grain in glulam and laminated veneer lumber of different timber species. Eur. J. Wood Prod. 2016;74:379-391.

[7] Coureau JL, Galimard P, Cointe A, Lartigau J, Morel S. Resistance-curves and wood variability: Application of glued-in-rod. International Journal of Adhesion and Adhesives 2016; 70:1-9

[8] Verdet M, Salenikovich A, Cointe A, Coureau J-L, Galimard P, Munoz Toro W, Blanchet P, Delisee C. Mechanical performance of polyurethane and epoxy adhesives in connections with glued-in rods at elevated temperatures. BioResources 2016; 11: 8200-8214.

[9] Fecht S, Vallée T, Tannert T, Fricke H. Adhesively Bonded Hardwood Joints under Room Temperature and Elevated Temperatures. Journal of Adhesion 2004; 90:401-419.

[10] Otero-Chans D, Estévez-Cimadevila J, Martín-Gutiérrez E, Vázquez-Rodríguez JA. Influence of timber density on the axial strength of joints made with glued-in steel rods: An experimental approach. International Journal of Adhesion and Adhesives 2010;30:380-385.

[11] Otero Chans D, EstévezCimadevila J, Martín Gutiérrez E. Influence of the geometric and material characteristics on the strength of glued joints made in chestnut timber. Materials and design 2009; 30: 1325-1332.

[12] Otero Chans D, EstévezCimadevila J, Martín Gutiérrez E. Glued joints in hardwood timber. International journal of adhesion and adhesives 2008; 28: 457-463.

[13] EstévezCimadevila J, Vázquez Rodríguez J.A., Otero Chans M.D. Experimental behaviour of threaded steel rods glued into high-density hardwood. International journal of adhesion and adhesives 2007; 27: 136-144.

[14] Tannert T, Zhu H, Myslicki S, Walther F, Vallée T. Tensile and fatigue investigations of timber joints with glued-in FRP rods. The Journal of Adhesion 2016; DOI: 10.1080/00218464.2016.1190653

[15] Otero-Chans D, Estévez-Cimadevila J, Martín-Gutiérrez E. Withdrawal strength of threaded steel rods glued with epoxy in wood. International Journal of Adhesion and Adhesives 2013;44:115-121.

[16] Rossignon A, Espion B. Experimental assessment of the pull-out strength of single rods bonded in glulam parallel to the grain. Holz Roh Werkst 2008; 66: 419-432.

[17] Yeboah D, Taylor S, McPolin D, Gilfillan R, Gilbert S. Behaviour of joints with bonded-in steel bars loaded parallel to the grain of timber elements. Construction and Building Materials 2011;25:2312-2317.

[18] Steiger R, Gehri E, Widmann R. Pull-out strength of axially loaded steel rods bonded in glulam parallel to the grain. Materials and Structures 2006;40:69-78. 
[19] Stepinac M, Rajcic V, Hunger F, van de Kuilen J-W, Tomasi R, Serrano E. CIBW18/46-7-10: Comparison of design rules for glued-in rods and design rule proposal for implementation in European standards. In: Proceedings of the CIB-W18 Meeting Forty-Six, Vancouver, Canada, 2013.

[20] Lartigau J, Coureau J-L, Morel S, Galimard P, Maurin E. Effect of temperature on the mechanical performance of glued-in rods in timber structures. International Journal of Adhesion\&Adhesives 2015;57:79-84.

[21] Lartigau J, Coureau J-L, Morel S, Galimard P. Mixed mode fracture of glued-in rods in timber structures. A new approach based on equivalent LEFM. Int J Fract 2015;192:71-86.

[22] Gustafsson PJ, Serrano E, Aicher S, Johansson CJ. A strength design equation for glued-in rods. In: Proceedings of the International RILEM Symposium, Germany, 2001, p 323-332.

[23] UNE-EN 1995-1-1:2016. Eurocode 5: Design of timber structures - Part 1-1: General - Common rules and rules for buildings. European Committee for Standardization Brussels, Belgium.

[24] Larse HJ. Properties affecting reliability design of timber structures. COST E24 Seminar on Reliability of timber structures Coimbra, Portugal, 4 - 5 May 2001.

[25] Ugolev BN. Wood as a natural smart material. Wood Science and Technology 2014; 48(3): 553 568. DOI 10.1007/s00226-013-0611-2

[26] Dubois F, Husson M, Sauvat N, Manfoumbi N. Modeling of the viscoelastic mechano-sorptive behavior in wood. Mechanics of Time-Dependent Materials 2012; 16 (4): 439-460

[27] Sorin E, Lanata F, Boudaud C. Behaviour of timber structures under variable environment through long-term monitoring. In: Proceedings of the World Conference on Timber Engineering, Vienna, Austria, 2016. ISBN: 978-390303900-1

[28] Huang Y. Creep behavior of wood under cyclic moisture changes: interaction between load effect and moisture effect. Journal of Wood Science2016; 62:392-399. DOI 10.1007/s10086-016$1565-4$

[29] Brokans A, Ozola L. Behaviour of creep of timber beams under natural environmental conditions. WIT Transactions on The Built Environment, 2014; 137: 479-489. DOI 10.2495/HPSM140441.

[30] Aicher S, Dill-Langer G. Influence of moisture, temperature and load duration on performance of glued-in rods. In: Proceedings of the international RILEM symposium on joints in timber structures, Stuttgart, Germany; 2001, p.383-392.

[31] Verdet M, Coureau J-L, Cointe A, Salenikovich A, Galimard P, Delisée C, Munoz Toro W. Creep performance of glued-in rods joints in controlled and variable climate conditions. International Journal of Adhesion \& Adhesives 2017; 75: 47-56.

[32] Custódio J, Broughton J, Cruz H. Rehabilitation of timber structures: novel test method to assess the durability of bonded-in rod connections. Materials and Structures 2012;45:199-221.

[33] Harris S. Fire Resistance of Epoxy-grouted Steel Rod Connections in Laminated Veneer Lumber (LVL). Fire Engineering Research Report 04/7. Ed. University of Canterbury, New Zealand. June 2004

[34] Di Maria V, D’Andria L, Muciaccia G, Ianakiev A. Influence of elevated temperature on glued-in steel rods for timber elements. Construction and Building Materials 2017; 147:457-465. DOI: 10.1016/j.conbuildmat.2017.04.038

[35] Aicher S., Wolf M., Dill-Langer G. Heat flow in a glulam joist with a glued-in steel rod subjected to variable ambient temperature, Otto-Graf-Journal 1998, 9:185-204.

[36] Broughton JG, Hutchinson AR. Effect of timber moisture content on bonded-in rods. Construction and Building Materials 2001;15:17-25.

[37] Cavalli A, Malavolti M, Morosini A, Salvini A, Togni M. Mechanical performance of full scale steel-timber epoxy joints after exposure to extreme environmental conditions. International Journal of Adhesion and Adhesives 2014; 54: 86-92. DOI: 10.1016/j.ijadhadh.2014.05.005

[38] CEN EN 14080: 2013. Timber structures. Glued laminated timber and glued solid timber. Requirements. European Committee for Standardization Brussels, Belgium. 
[39] UNE EN 1993-1-8:2008. Eurocode 3: Design of steel structures - Part 1-8: Design of joints. Asociación Española de Normalización y Certificación (AENOR).

[40] European Technical Approval ETA-04/o027. Deutches Institut für Bautechnick, Germany, 20 may 2009.

[41] Pierfrancesco V. Realistic shear assessment and novel strengthening of existing concrete bridges. Doctoral Thesis. University of Bath. November 2009.

[42] CEN EN ISO 9142:3003. Adhesives. Guide to the selection of standard laboratory ageing conditions for testing bonded joints European Committee for Standardization Brussels, Belgium.(June 2004).

[43] UNE EN 302-3:2005/A1:2006. Adhesives for load-bearing timber structures - Test methods Part 3: Determination of the effect of acid damage to wood fibres by temperature and humidity cycling on the transverse tensile strength.

[44] Kollman, F. (1959). Tecnología de la Madera y sus aplicaciones, Tomo 1. Ministerio de Agricultura, Instituto Forestal de Investigaciones y Experiencias, IFIE, Madrid.

[45] CEN EN 1990:2003/a1:2010. Eurocode - Basis of structural design. European Committee for Standardization Brussels, Belgium.

[46] Pralat K. Research on thermal conductivity of the wood and Analysis of results obtained by the hot wire method. Exp Tech 2016; 40:973-980.

[47] Martín-Gutiérrez E, Estévez-Cimadevila J, Otero-Chans D. Durability of joints made with threaded steel rods glued in chestnut timber - An experimental approach. Composites Part B, DOI: 10.1016/j.compositesb.2016.10.010

[48] Martín E, Estévez J, Otero D. Influence of geometric and mechanical parameters on stress states caused by threaded rods glued in wood. European Journal of Wood and Wood Products 2013; 71:259-266. 